\title{
Possum Scoring In Hollow Viscus Perforation.
}

\author{
Dr.Geethapriya. $S^{1}$, Dr.Kannan. ${ }^{2}$ \\ ${ }^{1}$ Assistanat Professor, Department Of General Surgery, Kilpauk Medical College. \\ ${ }^{2}$ Professor And HOD, Department Of General Surgery, Kilpauk Medical College
}

\begin{abstract}
Mortality and morbidity is an important and objective measure of outcome of a surgery. The outcome of surgical intervention is not solely dependent on the abilities of surgeon in isolation. The patients physiological status, disease that requires surgical corrections, severity of the diseases, the nature of the operation and the preoperative and postoperative support services have a major effect on the ultimate outcome. This POSSUM scoring (physiological and operative severity score for enumeration of mortality and morbidity) uses of the physiological and surgical variables which is a quick, noninvasive, easy to use and can be applied both in emergency and elective surgery and accurately in predicting the outcome.

Aim: Aim is to predict the risk of mortality and morbidity in patients with peritonitis due to hollow viscous perforation. Assessment of surgical risk in these patients is to help in choosing the modality of post operative management in a particular patient.

Materials And Methods: 50 patients with hollow viscous perforation admitted in Government Royapettah Hospital, Kilpauk Medical College Hospital from November 2014 to June 2015 were included in the study. Necessary date to be collected: POSSUM SCORE were to be calculated for each patient and analysis to be done.

Results: Based on my study, POSSUM can be used as a good stratification tool for predicting morbidity and mortality within 30 days from the operative day. One of the limitation in POSSUM is that it over predicts mortality in some low risk patients but prediction of morbidity is better. POSSUM scoring system is well validated for its use in risk adjusted auditing in general surg
\end{abstract}

\section{Validation Of Possum And P-Possum Equations}

Observed and the expected outcomes, derived from both POSSUM and P-POSSUM equation were correlated by using Pearson correlation coefficient. The resultant of Pearson correlation is shown in tables. Pearson correlation coefficient(r) measures the strength of association between two variables

The value of $r$ ranges between variables +1 and -1

$+1=$ A positive(direct correlation)

$-1=$ A negative(inverse correlation)

$0=\mathrm{A}$ zero correlation (no relationship)

Results are tested by Chi-square $\left(\mathrm{X}^{2}\right)$ test. Value of $\mathrm{P} \leq 0.05$ is significant

\section{Background}

Possum scoring system is a better risk stratification tool in predicting the mortality and morbidity of patients undergoing surgery for perforation peritonitis. Aim is to predict the risk of mortality and morbidity in patients with peritonitis due to hollow viscous perforation thereby evaluate the accuracy of POSSUM scoring systems in those patients. Assessment of surgical risk in these patients is to help in choosing the modality of post op management in a particular patient.

\section{Operational Definitions}

Mortality: Number of deaths within 30 days of surgery.

Morbidity:

Wound haemorrhage: Local haematoma requiring evacuation.

Deep haemorrhage: Postoperative bleeding requiring re-exploration.

Chest infection: Production of purulent sputum with positive bacteriological cultures, with or without chest radiography changes or pyrexia, or consolidation seen on chest radiograph. Wound infection: Wound cellulites or the discharge of purulent exudates.

Urinary infection: The presence of $>10{ }^{5}$ bacteria / $\mathrm{ml}$ with the presence of white cells in the urine, in previously clear

urine.

Deep infection: The presence of an intra-abdominal collection confirmed clinically or radiologically.

Septicemia: Positive blood culture. 
Pyrexia of unknown origin: Any temperature above $37^{\circ} \mathrm{C}$ for more than $24 \mathrm{~h}$ occurring after the original yrexia following surgery (if present) had settled, for which no obvious cause could be found.

Wound dehiscence: Superficial or deep wound breakdown.

Deep venous thrombosis and pulmonary embolus: when suspected, confirmed radiologically by venography or ventilation/ perfusion scanning or diagnosed at post mortem.

Cardiac failure: Symptoms or signs of left ventricular or congestive cardiac failure (alteration from preoperative measures).

Impaired renal function: Arbitrarily defined as an increase in blood urea of $>5 \mathrm{mmol} / 1$ from preoperative levels.

Hypotension: A fall in systolic blood pressure below $90 \mathrm{mmHg}$ for more than $2 \mathrm{H}$ as determined by sphygmomanometry or arterial pressure transducer measurement.

Respiratory failure: Respiratory difficulty requiring emergency ventilation.

Anastomotic leak: Discharge of bowel content via the drain, wound or abnormal orifice.

Possum: Physiology and operative severity score for enumeration of morbidity and mortality.

P-Possum: PORTSMOUTH POSSUM.

\section{Materials And Methods}

Patients who were underwent surgery for perforation peritonitis in Department of General surgery in our institution during the period from november 2014 to august 2015 were studied. This was a prospective study. Sample size was 50 patients.

\section{Inclusion criteria:}

Patients with clinical suspician and investigatory support for the diagnosis of peritonitis due to hollow viscous perforation who are later to be confirmed by intra operative findings.

\section{Exclusion criteria:}

1. Patients with hollow viscous perforation due to trauma.

2.Patients with any other significant illness which is likely to affect the outcome more than the disease in study.

\section{Data Collection}

Total 50 cases, who underwent emergency laparotomy for hollow viscous perforation. An informed consent was obtained from patients. Their demographic information's (age, sex, weight, etc) was recorded. The physiological variables like pulse rate, systolic blood pressure, respiratory rate, cardiac signs and Glasgow coma scale, hemoglobin, white blood count, Urea, Sodium, Potassium, ECG and CXR were recorded just before surgery. During the surgical procedure six operative variables including operative severity, total blood loss, multiple procedures, peritoneal soiling, cancer and mode of surgery were recorded by the operating surgeons. Their final physiological and operative score calculated from possum data sheet (attached). The predicted mortality and morbidity was calculated by POSSUM equation. After surgery the patient's observed mortality and morbidity were noted for one month and compared with the predicted outcomes. The patients were followed up for 1 month on $1^{\text {st }}, 3 \mathrm{rd}, 7 \mathrm{th}, 15 \mathrm{th}$, 30th post-operative days for morbidity (list attached in operational definitions) and mortality.

\section{Data analysis:}

All the information's gathered will be entered in the SPSS version 10.0 and analyzed. The source of the data will be 12 physiological variables i.e. age, pulse rate, systolic ,blood pressure, respiratory rate, cardiac signs, and Hb, W.B.C, Urea, Sodium, Potassium, and ECG \& six operative variables i.e. operative severity, total blood loss, multiple procedures, peritoneal soiling, cancer and mode of surgery were recorded. Demographic variables of the patients included in this study were analyzed using the simple descriptive statistics. Frequency distribution tables were made for source of data (emergency/elective). Final prediction of the mortality and morbidity of each patient was calculated using POSSUM calculator available on the internet and recorded.

The observed mortality and morbidity was recorded within 30 days post-operatively and compared with predicted outcomes Mortality and morbidity tables were made to calculate the observed/predicted (O/P) ratios. Pearson correlation was used to correlate the observed and predicted morbidity and mortality. Chi-square analysis was made for the test of significance. A p-value of .05 or less was taken as significant. 


\section{Results}

The main cause for perforation leading to surgery was peptic ulcer 50\%, Appendicular perforation $20 \%$, enteric fever $10 \%$, diverticulitis $7 \%$,TB $7 \%$, Strangulated hernia $3 \%$, foreign body $3 \%$.Mostly patients in emergency were male $(88 \%)$. Mean age of the emergency patients was 36 years $(\mathrm{SD} \pm 16.50)$ with age range from 15-75.

In emergency, sum of observed mortality and morbidity was $6(12 \%) \& 22(44 \%)$ while predicted mortality and morbidity by POSSUM was $9(18 \%) \& 28.17(56.34 \%)$ and P-POSSUM 6(12\%).The O/P ratio (observed / predicted) of mortality by POSSUM in laparotomy was .66 and for morbidity was .78 and by PPOSSUM, the mortality was 1.00 .

Pearson's correlation for POSSUM observed and predicted morbidity was $1.000 \& .736$ and mortality was $1.00 \& .707$ and for P-POSSUM was $1.000 \& .858$.

There was no significant difference between the observed and predicted values for morbidity $\left(\mathrm{x}^{2}=45.00\right.$, 24 df. $\mathrm{p}=$. 006), for POSSUM mortality $\left(\mathrm{x}^{2}=34.840,20 \mathrm{df} . \mathrm{p}=.021\right)$, and for P-POSSUM mortality $\left(\mathrm{x}^{2}=104.160\right.$, 14 df. $\mathrm{p}=.000)$

Tab 1. Indications for laparotomy

\begin{tabular}{|l|l|}
\hline & No. of patients \\
\hline Peptic ulcer & 15 \\
\hline Appendicular perforation & 6 \\
\hline Enteric fever & 3 \\
\hline Tuberculosis & 2 \\
\hline Diverticulum & 2 \\
\hline Obstructed hernia & 1 \\
\hline Foreign body & 1 \\
\hline
\end{tabular}

Tab 2: Complications Following Surgery

\begin{tabular}{|ll|}
\hline & Frequency \\
Wound infection & $5(10 \%)$ \\
Anastomotic leak & $2(4) \%$ \\
Wound Dehiscence & $3(6 \%)$ \\
Deep infection & $2(4 \%)$ \\
Sepsis & $1(2 \%)$ \\
Cardiac failure & $1(2 \%)$ \\
Chest infection & $1(2 \%)$ \\
Jaundice, Fistula & $1(2 \%)$ \\
Urinary fistula & $1(2 \%)$ \\
Pulmonary Embolus & $1(2 \%)$ \\
Liver failure & $1(2 \%)$ \\
Renal failure & $1(2 \%)$ \\
Burst Abdomen & $1(2 \%)$ \\
*UTI & $1(2 \%)$ \\
Total & $\mathbf{2 2}$ \\
\hline
\end{tabular}

*UTI: urinary tract infection

Tab.3.Age Distribution

\begin{tabular}{|l|l|l|}
\hline Age In Years & No.Of Cases & Percentage \\
\hline $\mathbf{1 5 - 3 0}$ & 27 & $54 \%$ \\
\hline $\mathbf{3 1 - 4 5}$ & 10 & $20 \%$ \\
\hline $\mathbf{4 6 - 6 0}$ & 7 & $14 \%$ \\
\hline $\mathbf{6 1 - 7 5}$ & 6 & $12 \%$ \\
\hline Total Number Of Patients & 50 & $100 \%$ \\
\hline
\end{tabular}

Fig 1. Graphical representation of age and gender distribution.

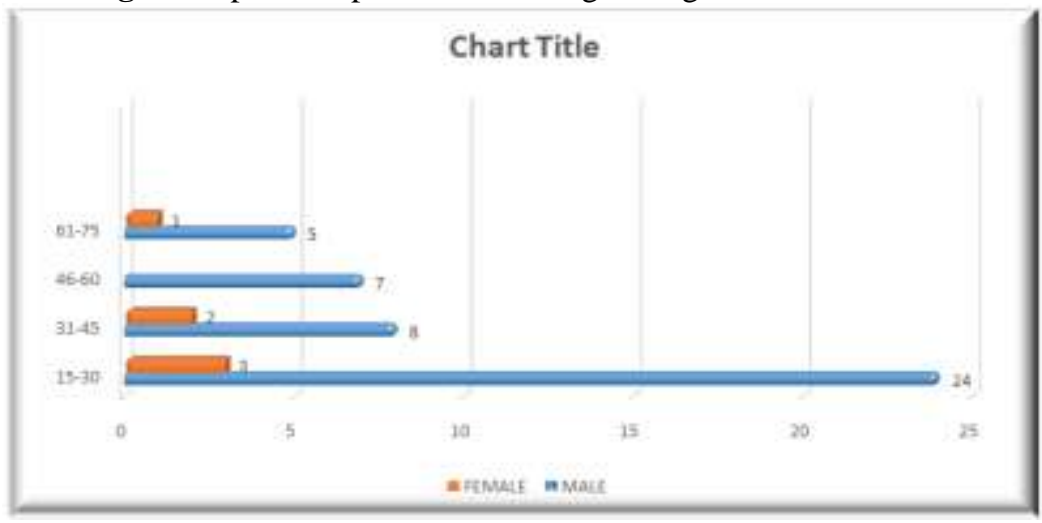


Tab 4. Sex distribution

\begin{tabular}{|l|l|}
\hline Sex & No.Of.Cases \\
\hline Men & 44 \\
\hline Women & 6 \\
\hline
\end{tabular}

Fig 2. Gender distribution.

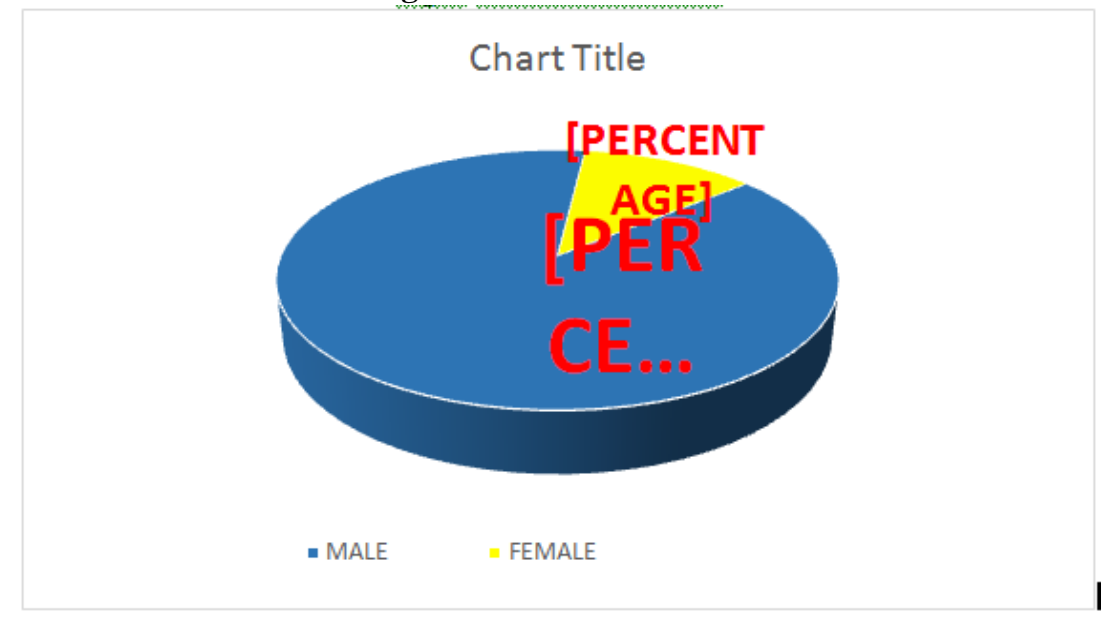

Fig 3. Etiological factors

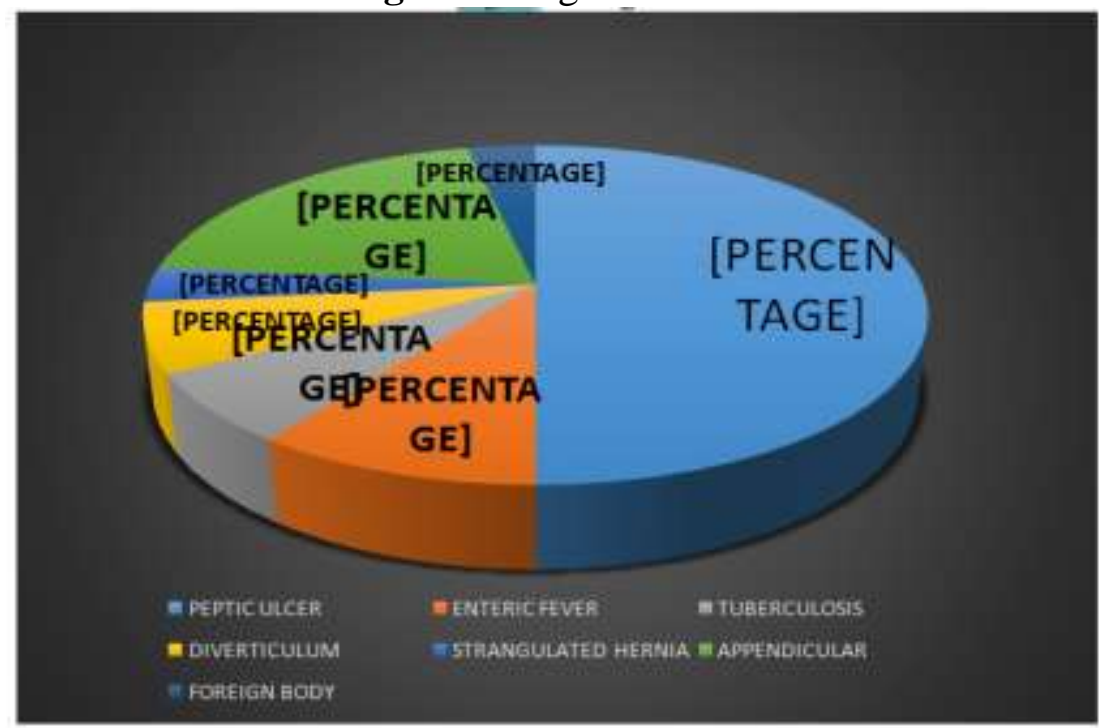

Fig 4. Complications following surgery

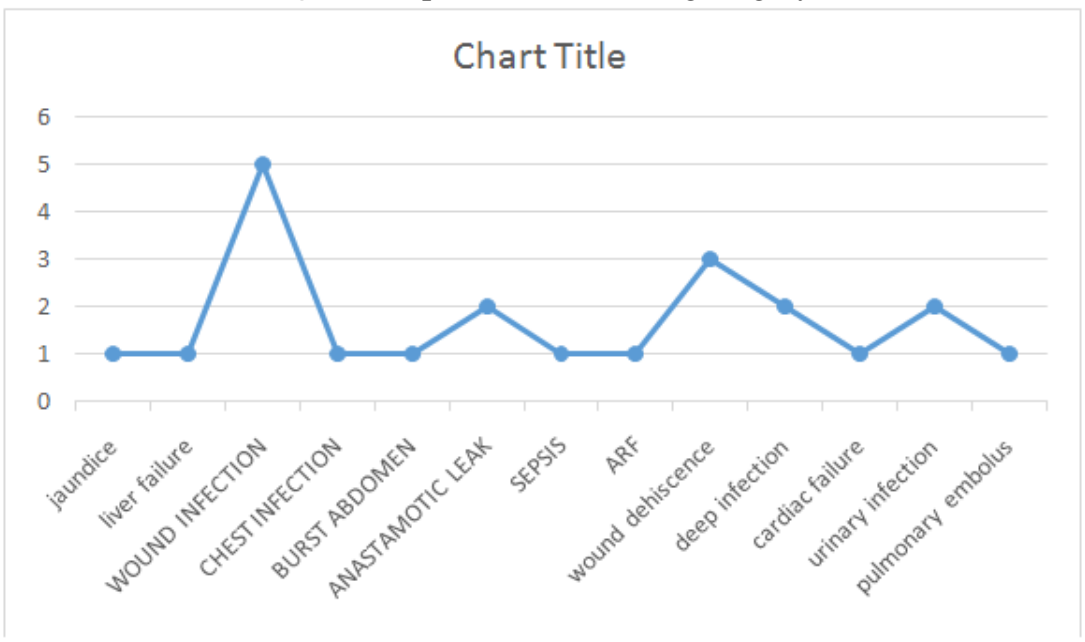


Tab 5:Sum Of Observed And Predicted Outcomes

Keys

\begin{tabular}{|l|l|l|l|l|}
\hline $\begin{array}{l}\text { O.morb } \\
\text { Sum }\end{array}$ & $\begin{array}{l}\text { O.mort } \\
\text { Sum }\end{array}$ & $\begin{array}{l}\text { P.morb } \\
\text { Sum }\end{array}$ & $\begin{array}{l}\text { P.mort } \\
\text { Sum }\end{array}$ & $\begin{array}{l}\text { PP.mort } \\
\text { Sum }\end{array}$ \\
\hline 22.00 & 6.00 & 28.17 & 9.00 & 6.00 \\
\hline
\end{tabular}

O.mort: observed mortality

O.morb:observed morbidity

P.mort: predicted mortality by POSSUM

P.morb: predicted morbidity by POSSUM

PP.mort:predicted mortality by p-possum

Tab 6.comparison of observed and predicted mortality using possum equation.

\begin{tabular}{|l|l|l|l|l|}
\hline $\begin{array}{l}\text { Range Of Age In } \\
\text { Years }\end{array}$ & Frequency & O.Mort & P.Mort & $\begin{array}{l}\text { O/P } \\
\text { Ratio }\end{array}$ \\
\hline $\mathbf{1 5 - 3 0}$ & 27 & 1 & 4.45 & .224 \\
\hline $\mathbf{3 1 - 4 5}$ & 10 & 1 & 1.56 & .64 \\
\hline $\mathbf{4 6 - 6 0}$ & 7 & 0 & 0.36 & 0 \\
\hline $\mathbf{6 1 - 7 5}$ & 6 & 4 & 2.63 & 1.52 \\
\hline & 50 & 6 & 9 & .66 \\
\hline
\end{tabular}

Keys

O.mort: observed mortality

P.mort: predicted mortality by POSSUM

$\mathbf{O} / \mathbf{P}$ :Observed/predicted

Tab 7.Comparison Of Observed And Predicted Morbidity Using Possum Equation

\begin{tabular}{|c|c|c|c|c|}
\hline \begin{tabular}{|llll} 
Range & Of & Age & In \\
Years & & & \\
\end{tabular} & Frequency & O.Morb & P.Morb & $\begin{array}{l}\text { O/P } \\
\text { Ratio }\end{array}$ \\
\hline $15-30$ & 27 & 9 & 15.04 & .59 \\
\hline 31-45 & 10 & 5 & 5.15 & .97 \\
\hline $46-60$ & 7 & 1 & 2.16 & .46 \\
\hline $61-75$ & 6 & 7 & 5.82 & 1.20 \\
\hline & 50 & 22 & 28.17 & .78 \\
\hline
\end{tabular}

Keys

O.morb:observed morbidity

P.morb: predicted morbidity by POSSUM

$\mathbf{O} / \mathbf{P} \quad$ : Observed/predicted

Tab 8.Comparison Of Observed And Predicted Mortality Using P-Possum Equation

\begin{tabular}{|l|l|l|l|l|}
\hline Range Of Age In Years & Frequency & O.Mort & Pp.Mort & $\begin{array}{l}\text { O/P } \\
\text { Ratio }\end{array}$ \\
\hline $\mathbf{1 5 - 3 0}$ & 27 & 1 & 2.41 & .41 \\
\hline $\mathbf{3 1 - 4 5}$ & 10 & 1 & .67 & 1.49 \\
\hline $\mathbf{4 6 - 6 0}$ & 7 & 0 & 0 & 0 \\
\hline $\mathbf{6 1 - 7 5}$ & 6 & 4 & 2.92 & 1.36 \\
\hline & 50 & 6 & 6 & 1 \\
\hline
\end{tabular}

Keys

O.mort: observed mortality

PP.mort: predicted mortality by P-POSSUM

$\mathbf{O} / \mathbf{P} \quad$ : Observed/predicted

Tab 9. Pearson's correlation in morbidity

\begin{tabular}{|l|l|l|l|}
\hline \multirow{3}{*}{ Observed morbidity } & Pearson Correlation & $\begin{array}{l}\text { Observed } \\
\text { morbidity }\end{array}$ & $\begin{array}{l}\text { Predicted } \\
\text { morbidity }\end{array}$ \\
\cline { 2 - 4 } & Sig. (2-tailed) & .000 & .736 \\
\cline { 2 - 4 } & $\mathrm{N}$ & 50 & .000 \\
\hline \multirow{3}{*}{ Predicted morbidity } & Pearson Correlation & .736 & 50 \\
\cline { 2 - 4 } & Sig. (2-tailed) & .000 & 1.000 \\
\cline { 2 - 4 } & $\mathrm{N}$ & 50 & 50 \\
\hline
\end{tabular}

** Correlation is significant at the 0.01 level (2-tailed). 
Tab 10. Pearson's correlation in mortality

\begin{tabular}{|l|l|l|l|}
\hline & & Observed mortality & Predicted mortality \\
\hline \multirow{2}{*}{$\begin{array}{l}\text { Observed } \\
\text { mortality }\end{array}$} & Pearson Correlation & 1.000 & .707 \\
\cline { 2 - 4 } & Sig. (2-tailed) &. & .000 \\
\cline { 2 - 4 } & $\mathrm{N}$ & 50 & 50 \\
\hline
\end{tabular}

Tab 11. Pearson's correlation in p-possum mortality

\begin{tabular}{|l|l|l|l|}
\hline & & $\begin{array}{l}\text { Observed } \\
\text { mortality }\end{array}$ & $\begin{array}{l}\text { Predicted } \\
\text { mortality }\end{array}$ \\
\hline \multirow{5}{*}{ Observed mortality } & Pearson Correlation & 1.000 & .858 \\
\cline { 2 - 4 } & Sig. (2-tailed) &. & .000 \\
\cline { 2 - 4 } & $\mathrm{N}$ & 50 & 50 \\
\hline \multirow{5}{*}{ Predicted mortality } & Pearson Correlation & .858 & 1.000 \\
\cline { 2 - 4 } & Sig. (2-tailed) & .000 &. \\
\cline { 2 - 4 } & $\mathrm{N}$ & 50 & 50 \\
\hline
\end{tabular}

** Correlation is significant at the 0.01 level (2-tailed)

\section{Conclusion}

Based on my study, POSSUM can be used as a good stratification tool for predicting morbidity and mortality within 30 days from the operative day. One of the limitation in POSSUM is that it over predicts mortality in some low risk patients but prediction of morbidity is better. POSSUM scoring system is well validated for its use in risk adjusted auditing in general surgery.

With this scoring system the outcome of the patient can be predicted and pre-operative counselling of the patient can be done. Not only that the care takers can be informed prior as a part of the informed consent and can be used for evaluation of the technique of pre-optimization in high risk patients. This study shows that although POSSUM over predicts the mortality in some low risk patients it is a good method of evaluation. Also P-POSSUM predicts the mortality in which is the major limiting factor POSSUM. This system can be applied for the surgical audit in our set up.

\section{Bibliography}

[1]. Mouret P, Francois Y, Vignal J, et al: Laparoscopic treatment of perforated peptic ulcer. Br J Surg 77:1006, 1990

[2]. Nathansom LK, Easter DW, Cuschieri A. Laparascopic repair/per toilet of perforated duodenal ulcer. Surgical Endoscopy 1990, Vol 233.

[3]. L aparoscopic Plication of Perforated Duodenal Ulcer

[4]. Laparoscopic Plication of Perforated Duodenal Ulcer. ....Nathansom LK, Easter DW, Cushieri

A. Laparascopic repair/peritoneal toilet of perforated duodenal ulcer. ...

[5]. Aboutplastic.surgery.uiowa.edu/surgery/ physpubs/lapofperforatedulcer.html - 13k - Cached - Similar pagE

[6]. Smith J J, Tekkis P. Risk Prediction in Surgery [online] 2003.available from URL:http://www.RiskPrediction.org.uk

[7]. Lam CM, Fan ST, Yuen AWC, Law WL, and Poon K. Validation of Possum scoring system for audit of major hepatectomy. Brjsurg 2004; 91: 450-4.

[8]. Mohil RS, Bhatnagar D, Bahadur L, Rajneesh, Dev KD, Magan M. Possum and P-Possum for risk adjusted audit of patients undergoing emergency laparotomy. Brjsurg r2004; 91: 500-3.

[9]. Tekkis PP, McCuloch P, Poloniecki JD, Prytherch DR, kessaris N, Stegar AC. Risk adjusted prediction of operative mortality in oesophagogastric surgery with O. Possum. Brjsurg 2004; 91: 288-95.

[10]. Brooks MJ, Sutton R, Sarin S. Comparison of surgical risk score, possum and p-possum in higher-risk patients. Brjsurg 2005; 92:1288-92.

[11]. Emberton M, Meulen J V D. an approach to surgical audit. In: Russell R C G, Norman S, Christopher JK editors. Bailey \& Love's short practice of surgery. $24^{\text {th }}$ ed. London: Arnold publishers 2004; 239-245.

[12]. Davidson, Schneider H J. Audit. In: Kirk RM, Ribbons WJ editors. Clinical surgery in general. Fourth ed. London: Churchill Livingstone publishers 2004; 428-435.

[13]. Goldacre MJ, Griffith M, Gill M, Mackintoch A. In-hospital deaths as a friction of all deaths within 30 days of hospital admission for surgery. Analysis of routine statics. BMJ 2002; 324:1069-70.

[14]. ANONYMOUS: NEW Classification of PHYSICAL Status. Anesthesiology 1963; $24: 111$.

[15]. Vacanti CJ, Houstn RJV, Hill RC. A statistical analysis of the relationship of post operative mortality in 63388 cases. Anesth Analog 1970; 49: 564-6.

[16]. Knauswa, Draper EA. Wagner DP. Zimmermam JE. APACHE II: a severity of disease classification system. Crit Care Med 1985; 9: 818-29.

[17]. Knauswa, Draper EA. Wagner DP. Zimmermam JE. APACHE III prognostic system. Risk prediction of hospital mortality for critically ill hospitalized adults. Chest 1991; 100:1619-36.

[18]. Copeland GP et al. POSSUM: a scoring system for surgical audit. Br J Surg1991; 78: 356-60.

[19]. Whiteley DR et al. An evaluation of the POSSUM surgical scoring System. Br J Surg, 1996; 83: 812-15.

[20]. Wijesinghe D et al. Comparison of POSSUM and the Portsmouth Predictor equation for predicting death following vascular surgery. Br J Surg 1998; 85:209-12.

[21]. Annual report 1999, Scottish Audit of Surgical Mortality

[22]. Gocmen E, Koc M, Keskek M, Kilie M, Ertan T. Evaluation of p-possum and o-possum in patients with gastric cancer undergoing resection.Hepatogastroentrology 2004; 51:1864-6.

[23]. Mahesh G, Gabriel R, Sunil K. Evaluation of P-Possum Mortality Predictor Equation and Its Use as a Tool in Surgical Audit. The Internet Journal of Surgery 2003; Volume 5 Number 1 
[24]. NagabhushanS,Srinath S, Weir F,AngersonW J, SugdenBA,Morran C G. Comparison of P-POSSUM and O-POSSUM in predicting mortality after oesophagogastricresections.Postgrad Med J 2007; 83: 355-58.

[25]. Wakabayashi H, Sano T, Yachida S, Okano k. Validation of risk assessment scoring systems for audit of elective surgery for gastrointestinal cancer in elderly patients. International journal of surgery 2007; 5: 323-27.

[26]. Jensen TC, Bosco C, LAWL. Evaluation of P-POSSUM in surgery for obstructing colorectal cancer and correlation of the predicted mortality with different surgical options. Diseases of the colon \& rectum 2005; 48: 493-98.

[27]. 23. Makoto W, Naokuni Y, Tomokazu Osamukamisaka N, Mitsuo T. Estimation of Mortality and Morbidity Risk in Colorectal Surgery using POSSUM Predictor Equation. Japanese Journal of Gastroenterological Surgery 2004; 37: 1714-20.

[28]. Pratt W, Joseph S, Callery M, Vollmer C. POSSUM accurately predicts morbidity for pancreatic resection. Surgery; 143:8-19.

[29]. Khan AW, Shah SR, Agarwal AK, Davidson BR. Evaluation of the POSSUM Scoring System for Comparative Audit in Pancreatic Surgery.DigSurg 2003; 20: 539-45

[30]. Midwinter M J, Tytherleigh M,Ashely S.Estimation of mortality and morbidity risk in vascular surgery using POSSUM and the Portsmouth predictor equation. Brjsurg 1999; 86: 471-74

[31]. Prytherch DR, Sutton GL, Boyle JR. Portsmouth POSSUM models for abdominal aortic aneurysm surgery. Br J Surg. 2001; 88: 958-63.

[32]. Ramanathan TS, Moppett IK, Wenn R, Moran CG. POSSUM scoring for patients with fractured neck of femur.BJA2005; 94: 43033.

[33]. Das N, Tallat AS, Naik R, Lopes AD, Godfrey KA, Hatem MH, Edmondson RJ. Risk adjusted surgical audit in gynecological oncology: P-POSSUM does not predict outcome. EJ SurgOnc 2006; 32: 1139-43.

[34]. Cagigas J, Escalante C, Angelo A, Hernandez. Application of the POSSUM System in Bariatric Surgery. Obesity Surgery 1999; $279-81$.

[35]. GriffithsH,Cuddihy P, DavisS,ParikhSA,Tomkinson. Risk-adjusted comparative audit. Is Possum applicable to head and neck surgery? Clin Otolaryngology \& Allied Sciences 2002; 27: 517-20.

[36]. Hobson S A,Sutton C D, Garcea G, Thomas W M. Prospective comparison of POSSUM and P-POSSUM with clinical assessment of mortality following emergency surgery. Actaanaesthesiologicascandinavica 2007; 51: 94-100.

[37]. Kiani QH, Hanif N, Khan MM. Surgical audit using Possum scoring system. J Surg Pak 2004; 9: 15-20.

[38]. Jawaid M, Masood Z, Iqbal SA. Postoperative complications in general surgical ward of teaching hospital. Pak J Med 2006; 22:1715 .

[39]. Joosse P, Soedarmo S, Luitse JS, PonsenKJ.Trauma outcome analysis of a Jakarta University Hospital using the TRISS method: validation and limitation in comparison with the Major Trauma Outcome Study. Trauma and Injury Severity Score.J Trauma 2001; 51:134-40.

[40]. Talwar S, Jain S, Porwal R, Laddha BL, Prasad P. Trauma scoring in a developing country. Singapore Med J 1999; 40: 386-8.

[41]. Qureshi MA. Polytrauma epidemiology \& prognosis versus trauma score. Professional Med J 2006; 13: 57-62.

[42]. 38.Aharonson-Daniel L, Giveon A, Stein M; Israel Trauma Group (ITG), Peleg K. Different AIS triplets: Different mortality predictions in identical ISS and NISS. J Trauma 2006; 61: 711-7.

[43]. 39. Nijboer JM, van der Sluis CK, van der Naalt J, Nijsten MW, Ten Duis HJ. Two cohorts of severely injured trauma patients, nearly two decades apart: unchanged mortality but improved quality of life despite higher age.J Trauma 2007; 63: 670-5.

[44]. 40. Edward J. Hanrahan, GangadharMadupu.Epidemiology and Biostatistics for USMLE. 1st ed. USA: Appleton \& Lange; 1994

[45]. 41. Prytherch DR, Whitely MS, Higgins B, Weaver PC, Prout WG, Powell SJ. Possum and Portsmouth Possum for predicting mortality. Br J Surg 1998; 85:1217-20.

[46]. 42. Whitely MS, Prytherch DR, Higgins et al. An evaluation of the Possum surgical scoring system. Br J Surg1996; 83: 812-15.

[47]. 43. Sagar PM, Harthy MN, Mancey et al. Comparative audit of colorectal resection with the POSSUM scoring system.

[48]. Br J Surg 1994; 81:1492-94. 